\title{
Evolution of operative techniques and perfusion strategies for minimally invasive mitral valve repair
}

\author{
Eugene A. Grossi, MD, Didier F. Loulmet, MD, Charles F. Schwartz, MD, Patricia Ursomanno, PhD, \\ Elias A. Zias, MD, Sophia L. Dellis, BA, and Aubrey C. Galloway, MD
}

\begin{abstract}
Objective: Perfusion strategies and operative techniques for minimally invasive mitral valve repair have evolved over time. During the past decade, our institution's approach has progressed from a port access platform with femoral perfusion to predominantly a central aortic cannulation through a right anterior minithoracotomy incision. We analyzed this institutional experience to evaluate the impact of approach on patient outcomes.
\end{abstract}

\begin{abstract}
Methods: Between 1995 and 2007, 1282 patients (mean age, 59.3 years; range, 18-99 years) underwent firsttime, isolated mitral valve repair using a minimally invasive technique. Patient demographics included peripheral vascular disease $(3.2 \%)$, chronic obstructive pulmonary disease $(8.3 \%)$, atherosclerotic aorta $(6.5 \%)$, cerebrovascular disease $(4.3 \%)$, and ejection fraction less than 30\% (4.3\%). Retrograde perfusion was performed in 394 (30.7\%) of all patients and endoaortic balloon occlusion in $373(29.1 \%)$; the operative technique was a right anterior minithoracotomy in $1264(98.6 \%)$ and left posterior minithoracotomy in $18(1.4 \%)$. The etiology of mitral disease was degenerative in $73.2 \%$, functional in $20.6 \%$, and rheumatic in $2.4 \%$. Data were collected prospectively using the New York State Cardiac Surgery Report System and a customized minimally invasive surgery data form. Logistic analysis was used to evaluate risk factors and outcomes; operative experience was divided into tertiles.
\end{abstract}

Results: Overall hospital mortality was $2.0 \%$ (25/1282). Mortality was $1.1 \%$ (10/939) for patients with degenerative etiology and $0.4 \%$ (3/693) for patients younger than 70 years of age with degenerative valve disease. Risk factors for death were advanced age $(P=.007)$, functional etiology $(P=.010$; odds ratio $[\mathrm{OR}]=3.3)$, chronic obstructive pulmonary disease $(P=.013 ; \mathrm{OR}=3.4)$, peripheral vascular disease $(P=.014 ; \mathrm{OR}=4.2)$, and atherosclerotic aorta $(P=.03 ; \mathrm{OR}=2.8)$. Logistic risk factors for neurologic events were advanced age $(P$ $=.02)$, retrograde perfusion $(P=.001 ; \mathrm{OR}=3.8)$, and emergency procedure $(P=.01 ; \mathrm{OR}=66.6)$. Interaction modeling revealed that the only significant risk factor for neurologic event was the use of retrograde perfusion in high-risk patients with aortic disease $(P=.04 ; \mathrm{OR}=8.5)$. Analysis of successive tertiles during this 12 -year experience revealed a significant decrease in the use of retrograde arterial perfusion $(89.6 \%, 10.4 \%$, and $0.0 \% ; P<.001)$ and endoaortic balloon occlusion $(89.3 \%, 10.7 \%$, and $0 \% ; P<.001)$. The overall frequency of postoperative neurologic events was $2.3 \%$ (30/1282) and decreased from $4.7 \%$ in the first tertile to $1.2 \%$ in the second and third tertiles $(P<.001)$.

Conclusions: Central aortic cannulation through a right anterior minithoracotomy for mitral valve repair allows excellent outcomes in patients with a broad spectrum of comorbidities and has become our preferred approach for most patients undergoing mitral valve repair. Retrograde arterial perfusion is associated with an increased risk of stroke in patients with severe peripheral vascular disease and should be reserved for select patients without significant atherosclerosis. (J Thorac Cardiovasc Surg 2012;143:S68-70)

Perfusion strategies and operative techniques for minimally invasive mitral valve repair have evolved over

From the Department of Cardiothoracic Surgery, New York University Medical Center, New York, NY.

Disclosures: Eugene A. Grossi, Didier F. Loulmet, Charles F. Schwartz, Patricia Ursomanno, Elias A. Zias, Sophia L. Dellis, and Aubrey C. Galloway have nothing to disclose with regard to commercial support.

Presented at The American Association for Thoracic Surgery Mitral Conclave, New York, New York, May 5-6, 2011.

Received for publication May 1, 2011; revisions received Nov 13, 2011; accepted for publication Jan 4, 2012; available ahead of print Jan 30, 2012.

Address for reprints: Eugene A. Grossi, MD, New York University Medical Center, 530 First Ave, Suite 9V, New York, NY 10016 (E-mail: eugene.grossi@nyumc. org).

0022-5223/\$36.00

Copyright (C) 2012 by The American Association for Thoracic Surgery doi:10.1016/j.jtcvs.2012.01.011 time; concomitantly, strategies for arterial perfusion have changed in accordance with the reduced incision size. During the past decade, our institution's approach has progressed from initially a port access platform with femoral perfusion to central aortic cannulation through a right anterior minithoracotomy incision. This report analyzes our perfusion and incision approaches for first-time, isolated minimally invasive mitral valve repairs and their outcomes.

\section{PATIENTS AND METHODS \\ Clinical Characteristics}

This retrospective study was approved by the New York University School of Medicine Institutional Review Board with a specific waiver of individual patient consent. From 1995 through 2007, 1282 patients 


\section{Abbreviations and Acronyms \\ $\mathrm{CI}=$ confidence interval \\ $\mathrm{OR}=$ odds ratio}

underwent first-time, isolated mitral valve repair using a minimally invasive technique. The etiology of mitral disease was degenerative in $73.2 \%$, functional in $20.6 \%$, and rheumatic in $2.4 \%$. Patients had a mean age of 59.3 years (range, 18-99 years.). Patient demographics included peripheral vascular disease $(3.2 \%)$, chronic obstructive pulmonary disease $(8.3 \%)$, atherosclerotic aorta $(6.5 \%)$, cerebrovascular disease $(4.3 \%)$, and ejection fraction less than $30 \%(4.3 \%)$.

\section{Surgical Techniques}

Operative technique consisted of a right anterior minithoracotomy ${ }^{1}$ in $1264(98.6 \%)$ patients and a left posterior minithoracotomy ${ }^{2}$ in 18 $(1.4 \%)$. Retrograde perfusion was performed in $394(30.7 \%)$ of all patients and endoaortic balloon occlusion was performed in 373 (29.1\%). Initially, a port access perfusion approach ${ }^{3}$ was used in patients without evidence of atheromatous disease of the thoracic aorta or obstructive peripheral arterial disease. Subsequently, perfusion strategy shifted toward central aortic cannulation through the right minithoracotomy incision. Surgical techniques were standardized during this study period; only carbon dioxide insufflation was added midway during this experience.

\section{Data Analysis}

Data were prospectively collected using the New York State Cardiac Surgery Report System and a customized minimally invasive surgery data collection instrument. Mortality was death before hospital discharge or within 30 days of operation. Stroke was defined as a new, permanent deficit, a transient deficit lasting greater than 24 hours, or a new lesion on cerebral imaging. Operative experience was divided into chronologic tertiles based on date of operation. Statistical analysis was performed using IBM SPSS Statistics 19 software (IBM, Somers, NY), and logistic analysis was used to evaluate risk factors and outcomes. We had full access to the data and take full responsibility for its integrity.

\section{RESULTS}

Overall hospital mortality for minimally invasive mitral valve repair was $2.0 \%(25 / 1282)$. Mortality for patients with degenerative etiology was $1.1 \%$ (10/939) and for patients younger than 70 years of age with degenerative valve disease mortality, $0.4 \%$ (3/693). Multivariable analysis revealed that risk factors for hospital death were advanced age $(P=.007)$, functional etiology $(P=.010$; odds ratio [OR] $=3.3)$, chronic obstructive pulmonary disease $(P=.013$; $\mathrm{OR}=3.4)$, peripheral vascular disease $(P=.014$; $\mathrm{OR}=$ $4.2)$, and atherosclerotic aorta $(P=.03$; $\mathrm{OR}=2.8)$ (Table 1). Initial analysis of risk factors for neurologic events revealed associations with advanced age $(P=.02)$, retrograde perfusion $(P=.001 ; \mathrm{OR}=3.8 ; 95 \%$ confidence interval $[\mathrm{CI}]=1.7-8.1)$, and emergency procedure $(P=.01$; OR $=66.6 ; 95 \% \mathrm{CI}=3.6-1000$ ) (Table 1 ). Further analysis was performed by identifying patients in whom retrograde arterial perfusion was typically considered a "high risk": those with peripheral vascular disease, cerebrovascular disease, dialysis, and atherosclerotic aortas. Logistic regression with bootstrapping revealed that the most and only significant risk factor for a neurologic event was the use of retrograde perfusion in high-risk patients with disease of the aorta $(P=.04 ; \mathrm{OR}=8.5 ; 95 \% \mathrm{CI}=1.1-72)$.

Analysis of the successive tertiles during this 12-year experience revealed a significant decrease in the use of retrograde arterial perfusion $(89.6 \%, 10.4 \%, 0.0 \% ; P<.001)$ and endoaortic balloon occlusion $(89.3 \%, 10.7 \%, 0.0 \%$; $P<.001)$. The overall frequency of postoperative neurologic events was $2.3 \%(30 / 1282)$ and decreased from $4.7 \%$ in the first tertile to $1.2 \%$ in the second and third tertiles $(P<.001)$.

\section{DISCUSSION}

A recent Society of Thoracic Surgeons Adult Cardiac Surgery Database analysis ${ }^{4}$ associated "less invasive mitral valve surgery" with similar mortality (as opposed to sternotomy) and with almost double the risk of stroke. The strength of this association, however, was questionable owing to the imprecise definition of "less invasive surgery." In response, we $\mathrm{w}^{5}$ recently critically reevaluated these findings by reviewing a large minimally invasive valve experience using precise data definitions. Our report "uncoupled" outcomes by strictly and separately analyzing incision location and arterial perfusion strategy; it demonstrated that adverse neurologic outcomes were not associated with incision location but were increased with the use of retrograde perfusion. In particular, the use of retrograde arterial perfusion in the setting of vascular disease demonstrated the greatest risk for neurologic complication.

This current report focuses on a more homogeneous subset of operations (first-time mitral valve repairs) and the changes in perfusion strategies for these patients. Firsttime mitral surgery typically involves a group of patients with low risk of neurologic complication as evidenced by the $1.2 \%$ incidence of postoperative stroke in our more recent cohorts. This is in contrast to complex mitral surgery in the setting of prior cardiac operations, where neurologic complications can range from $3.8 \%{ }^{6}$ to $7.5 \%{ }^{7}$ With the great majority of our mitral patients being operated on by a right minithoracotomy, we now rely primarily on direct ascending aortic cannulation to provide antegrade arterial perfusion and obviate concerns associated with retrograde perfusion.

Our data set suggests that if in older patients a femoral perfusion technique is chosen, preoperative evaluation of the aorta and distal vasculature would be indicated to demonstrate that a given patient would not be at increased neurologic risk. This would include computed tomographic angiography of the aorta with runoff and transesophageal echocardiographic evaluation of the descending aorta. Such a thoughtful screening approach has been used by Murphy and associates ${ }^{8}$ for their patients having robotic mitral surgery, with a reported stroke rate of $1.6 \%$. 
TABLE 1. Multivariable analysis of complications in 1282 patients undergoing primary minimally invasive mitral valve repairs

\begin{tabular}{lcc}
\hline & Odds ratio & $\boldsymbol{P}$ value \\
\hline Risk factors for death & & \\
Increased age & N/A & .007 \\
Functional mitral insufficiency & 3.3 & .010 \\
Chronic obstructive pulmonary disease & 3.4 & .013 \\
Peripheral vascular disease & 4.2 & .014 \\
Atherosclerotic aorta & 2.8 & .03 \\
Risk factors for neurologic events (simple logistic model) & \\
Increased age & N/A & .02 \\
Retrograde arterial perfusion & 3.8 & .001 \\
Emergency procedure & 66.6 & .01 \\
Risk factors for neurologic events bootstrapped, interaction model \\
Retrograde perfusion in high risk aorta & 8.5 & .04 \\
Increased age & N/A & .11 \\
Emergency procedure & 1.6 & .09 \\
\hline
\end{tabular}

N/A, Not available.

\section{CONCLUSIONS}

A right anterior minithoracotomy with central aortic cannulation has become our "go-to" strategy for the majority of patients undergoing isolated mitral valve repair. This strategy is associated with a low risk of neurologic complications and excellent clinical outcomes. Retrograde arterial perfusion in older patients with peripheral vascular disease or disease of the aorta is associated with an increased risk of stroke; however, this strategy is not associated with an increased risk of stroke in other patient cohorts. We therefore reserve retrograde perfusion for select patients without significant peripheral vascular or aortic atherosclerotic disease.

\section{References}

1. Grossi EA, Galloway AC, LaPietra A, Ribakove GH, Ursomanno P, Delianides J, et al. Minimally invasive mitral valve surgery: a 6-year experience with 714 patients. Ann Thorac Surg. 2002;74:660-3; discussion 663-4.

2. Saunders PC, Grossi EA, Sharony R, Schwartz CF, Ribakove GH, Culliford AT, et al. Minimally invasive technology for mitral valve surgery via left thoracotomy: experience with forty cases. J Thorac Cardiovasc Surg. 2004; $127: 1026-32$.

3. Grossi EA, Ribakove G, Schwartz DS, Galloway AC, Colvin SB. "Port Access" approach for minimally invasive mitral valve surgery. Op Tech Thorac Cardiovasc Surg. 1998;3:32-46.

4. Gammie JS, Zhao Y, Peterson ED, O’Brien SM, Rankin JS, Griffith BP. J. Maxwell Chamberlain Memorial Paper for adult cardiac surgery. Less-invasive mitral valve operations: trends and outcomes from the Society of Thoracic Surgeons Adult Cardiac Surgery Database. Ann Thorac Surg. 2010;90:1401-8. 10 e1; discussion 1408-10.

5. Grossi E, Loulmet D, Schwartz C, Solomon B, Dellis S, Balsam L, et al. Minimally invasive valve surgery with antegrade perfusion strategy is not associated with increased neurologic complications. Ann Thorac Surg. 2011;92:1346-9; discussion 1349-50.

6. Crooke GA, Schwartz CF, Ribakove GH, Ursomanno P, Gogoladze G, Culliford AT, et al. Retrograde arterial perfusion, not incision location, significantly increases the risk of stroke in reoperative mitral valve procedures. Ann Thorac Surg. 2010;89:723-9; discussion 729-30.

7. Svensson LG, Gillinov AM, Blackstone EH, Houghtaling PL, Kim KH, Pettersson GB, et al. Does right thoracotomy increase the risk of mitral valve reoperation? J Thorac Cardiovasc Surg. 2007;134:677-82.

8. Murphy DA, Miller JS, Langford DA, Snyder AB. Endoscopic robotic mitral valve surgery. J Thorac Cardiovasc Surg. 2006;132:776-81. 